\title{
OPEN Prevalence of Toxoplasma gondii infection among small mammals in Tatarstan, Russian Federation
}

\author{
Nikolai D. Shamaev ${ }^{1,2}$, Eduard A. Shuralev ${ }^{1,3,5}$, Oleg V. Nikitin' ${ }^{1}$, Malik N. Mukminov ${ }^{1,3}$, \\ Yuriy N. Davidyuk ${ }^{1}$, Alexander N. Belyaev ${ }^{6}$, Guzel Sh. Isaeva, ${ }^{7,8}$, Vasil B. Ziatdinov, \\ Nail I. Khammadov ${ }^{4,5}$, Regina F. Safina ${ }^{4}$, Gaysha R. Salmanova ${ }^{4}$, Guzel M. Akhmedova ${ }^{3}$, \\ Kamil S. Khaertynov ${ }^{3,4}$, Taizo Saito ${ }^{9}$, Katsuya Kitoh ${ }^{2,9,10}$ \& Yasuhiro Takashima ${ }^{2,9,10 凶}$
}

Toxoplasma gondii is a zoonotic parasite with a wide host range that includes humans, domestic animals and wild animals. Small mammals serve as intermediate hosts for $T$. gondii and may contribute to the persistence of this parasite in the environment. Mass mortality in wild animals and deaths in rare endemic species make the study of this parasite of growing importance. In this study, $T$. gondii infection prevalence was evaluated in brain tissues from 474 small mammals captured at 26 trapping points in urban and rural areas of Tatarstan, Russian Federation. Nested PCR was used to detect the $T$. gondii B1 gene in the samples. Overall, $40 / 474$ samples (8.44\%) showed B1 gene positivity. T. gondii infection among the wild small mammals trapped in the rural area was significantly higher as a whole than that of the urban area as a whole. Multivariate logistical regression analysis also showed that the trapping area (rural or urban) significantly contributed to $T$. gondii positivity. Vegetation in the trapping points, small mammal species, sex, age or distance from the trapping points to the nearest human settlements did not significantly affect $T$. gondii positivity in the sampled small mammals.

Toxoplasma gondii is one of the most wide-spread parasites in the world. With its broad-host-range, it infects almost all mammals and birds including humans, domestic animals and wild animals. Although toxoplasmosis in humans and domestic animals is not usually symptomatic ${ }^{1}$, mass mortality in wild animals and deaths in rare endemic species have been reported ${ }^{2-7}$. Hence, attempts to understand the prevalence of $T$. gondii in wild animals are warranted. In a study conducted in Panama City, it was reported that $T$. gondii prevalence among small mammals was higher than in humans and birds from the same area ${ }^{8}$. Cats, the definitive hosts for T. gondii, shed huge numbers of environmentally-resistant oocysts in their feces, and small mammals are more frequently preyed upon by domestic cats than other intermediate hosts ${ }^{9}$. Therefore, it is important to understand the status of T. gondii prevalence among wild small mammals to understand the local situation for T. gondii distribution.

Tatarstan, Russian Federation is located on the East European Plain in the middle reaches of the Volga River (Fig. 1A). In this area, the Volga-Kama Nature Reserve in Tatarstan contains approximately a quarter of the World's animal species ${ }^{10}$. Understanding the situation regarding infectious pathogens among wild animals in Tatarstan is therefore worthwhile. We have previously reported the high seroprevalence of toxoplasmosis in humans, cats and domestic animals in Tatarstan, including in the capital city, Kazan ${ }^{11,12}$. However, very little is

${ }^{1}$ Institute of Environmental Sciences, Kazan Federal University, 18 Kremlyovskaya St, Kazan, Tatarstan, Russian Federation 420008. 'Joint Graduate School of Veterinary Sciences, Gifu University, 1-1 Yanagido, Gifu 501-1193, Japan. ${ }^{3}$ Kazan State Medical Academy - Russian Medical Academy of Continuous Professional Education, 36 Butlerova St, Kazan, Tatarstan, Russian Federation 420012. ${ }^{4}$ Federal Center for Toxicological, Radiation and Biological Safety, Nauchniy Gorodok-2, Kazan, Tatarstan, Russian Federation 420075. ${ }^{5}$ Kazan State Academy of Veterinary Medicine by N.E. Bauman, 35 Sibirskiy Trakt St., Kazan, Tatarstan, Russian Federation 420029. ${ }^{6}$ Institute of Fundamental Medicine and Biology, Kazan Federal University, 18 Kremlyovskaya St, Kazan, Tatarstan, Russian Federation 420008. ${ }^{7}$ Kazan Research Institute of Epidemiology and Microbiology, Rospotrebnadzor, 67 Bolshaya Krasnaya, Kazan, Tatarstan, Russian Federation 420015. ${ }^{8}$ Department of Microbiology, Kazan State Medical University, Kazan, Tatarstan, Russian Federation 420012. ${ }^{9}$ The United Graduate School of Veterinary Sciences, Gifu University, 1-1 Yanagido, Gifu 501-1193, Japan. ${ }^{10}$ Department of Veterinary Parasitology, Faculty of Applied Biological Science, 1-1 Yanagido, Gifu 501-1193, Japan. ${ }^{\boxplus}$ email: atakashi@gifu-u.ac.jp 

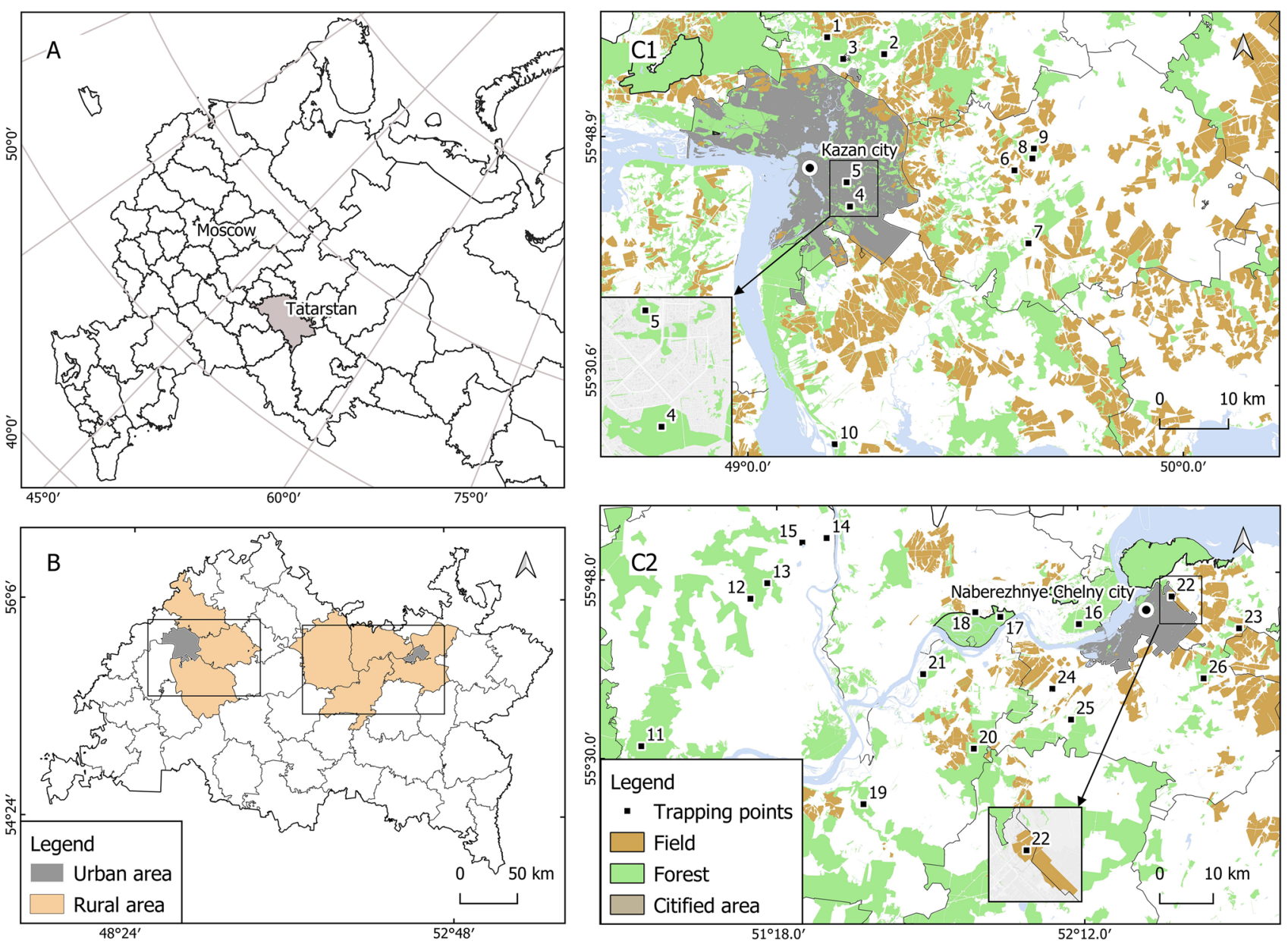

Figure 1. Map of the trapping points in Tatarstan, Russian Federation. (A) Overview map of the European part of Russian Federation showing the location of Tatarstan. (B) Administrative boundaries of urban (gray) and rural areas (beige). C1-C2. Spatial referencing of sampling sites: forests (green), fields (brown), citified area (gray). Locations of the urban areas appear as larger approximations in separate windows. Each trapping point is indicated by a number. Set of vector data layers was purchased from NextGIS (OpenStreetMap and contributors, 2021. Data license: ODbL. Accessed via https://data.nextgis.com).

known about T. gondii prevalence among wild animals. Thus, in this study, we investigated T. gondii infection prevalence among wild small mammals in the Tatarstan.

\section{Results}

T. gondii prevalence among small mammals in Tatarstan, Russian Federation. To assess the prevalence of T. gondii among small mammals in Tatarstan, Russian Federation, we captured 474 of these animals at 26 trapping places (Fig. 1, Supplementary Table S1) and detected the T. gondii B1 gene in brain DNA from them using nested PCR. Altogether, 40/474 (8.44\%, 95\% confidence interval; CI: [6.16-11.4]) of the brain samples from the small mammals showed T. gondii B1 gene positivity (Table 1). We found that $13.56 \%(24 / 176)$ and $5.37 \%(16 / 298)$ of the small mammals trapped in the rural and urban areas showed T. gondii positivity, respectively, $16.66 \%(2 / 12)$ and $8.35 \%(38 / 455)$ of the individuals trapped in fields and forests, respectively, were positive, and $6.04 \%(9 / 149)$ and $4.16 \%(6 / 144)$ were male and female, respectively. T. gondii positivity among their ages was $8.77 \%$ (5/57) for juveniles (aged 0-2 months), 3.94\% (5/127) for mature adults (aged 3-6 months), and $6.17 \%$ (10/162) for adults (aged > 6 months). Positivity among the small mammal species was 7.95\% (24/302) for Myodes glareolus (hereafter called My. glareolus), 12.50\% (1/8) for Apodemus agrarius, $11.29 \%$ (14/124) for A. uralensis, and 9.09\% (1/11) for A. flavicollis. Although five Microtus arvalis (hereafter called Mi. arvalis), 13 Sorex araneus, and one Dryomys nitedula were also examined, no individuals showed T. gondii positivity. The distances from the trapping points to the nearest human settlements varied by $170-3890 \mathrm{~m}$. As shown in Fig. 2, unlike reports from other regions ${ }^{2}$, no clear correlation was found between proximity to human settlements and high infection rates.

Risk factors for T. gondii infection. We performed multivariate logistic regression analysis to separately validate the following as risk factors for T. gondii infection: trapping point area (urban or rural), vegeta- 


\begin{tabular}{|c|c|c|c|c|c|c|c|}
\hline \multicolumn{3}{|c|}{ AreaCategory } & \multirow{2}{*}{\begin{tabular}{|l|} 
Examined \\
294
\end{tabular}} & \multirow{2}{*}{$\begin{array}{l}\text { Positive } \\
15\end{array}$} & \multirow{2}{*}{\begin{tabular}{|l|} 
Negative \\
279
\end{tabular}} & \multirow{2}{*}{$\begin{array}{l}\text { Prevalence (\%) } \\
7.95\end{array}$} & \multirow{2}{*}{$\begin{array}{l}\text { 95\% CI } \\
5.26-11.74\end{array}$} \\
\hline \multirow{11}{*}{ Area } & \multirow{3}{*}{ Urban } & Kazan city & & & & & \\
\hline & & Naberezhnye Chelny city & 3 & 1 & 2 & 33.33 & $1.76-87.46$ \\
\hline & & Unknown & 1 & 0 & 1 & 0 & $0-94.54$ \\
\hline & \multirow{8}{*}{ Rural } & Vysokogorsky district & 22 & 1 & 21 & 4.54 & $0.24-24.88$ \\
\hline & & Pestrechinsky district & 17 & 3 & 15 & 17.64 & $4.67-44.2$ \\
\hline & & Laishevsky district & 16 & 3 & 13 & 18.75 & $4.97-46.3$ \\
\hline & & Mamadyshsky district & 40 & 5 & 35 & 12.5 & $4.7-27.6$ \\
\hline & & Yelabuzhsky district & 14 & 1 & 13 & 7.14 & $0.37-35-8$ \\
\hline & & Nizhnekamsky district & 37 & 6 & 31 & 16.21 & $6.77-32.68$ \\
\hline & & Tukayevsky district & 25 & 5 & 20 & 20 & $7.6-41.3$ \\
\hline & & Unknown & 5 & 0 & 5 & 0 & $0-53.7$ \\
\hline \multirow{6}{*}{ Vegetation } & \multirow{2}{*}{ Urban } & Forest & 294 & 15 & 279 & 7.95 & $5.26-11.74$ \\
\hline & & Field & 3 & 1 & 2 & 33.33 & $1.76-87.46$ \\
\hline & \multirow{4}{*}{ Rural } & Unknown & 1 & 0 & 1 & 0 & $0-94.54$ \\
\hline & & Forest & 161 & 23 & 138 & 14.29 & 9.45-20.87 \\
\hline & & Field & 9 & 1 & 8 & 11.11 & $0.58-49.33$ \\
\hline & & Unknown & 6 & 0 & 6 & 0 & $0-48.32$ \\
\hline \multirow{3}{*}{ Sex } & \multicolumn{2}{|l|}{ Male } & 149 & 9 & 140 & 6.04 & $2.97-11.5$ \\
\hline & \multicolumn{2}{|c|}{ Female } & 144 & 6 & 138 & 4.16 & $1.7-9.24$ \\
\hline & \multicolumn{2}{|c|}{ Unknown } & 181 & 25 & 156 & 13.81 & $9.3-19.9$ \\
\hline \multirow{8}{*}{ Species } & \multicolumn{2}{|c|}{ Myodes glareolus } & 302 & 24 & 278 & 7.95 & $5.26-11.74$ \\
\hline & \multicolumn{2}{|c|}{ Apodemus uralensis } & 124 & 14 & 110 & 11.29 & $6.54-18.53$ \\
\hline & \multicolumn{2}{|c|}{ Apodemus agrarius } & 8 & 1 & 7 & 12.5 & $0.65-53.32$ \\
\hline & \multicolumn{2}{|c|}{ Microtus arvalis } & 5 & 0 & 5 & 0 & $0-53.7$ \\
\hline & \multicolumn{2}{|c|}{ Sorex araneus } & 13 & 0 & 13 & 0 & $0-28.34$ \\
\hline & \multicolumn{2}{|c|}{ Apodemus flavicollis } & 11 & 1 & 10 & 9.09 & $0.47-42.88$ \\
\hline & \multicolumn{2}{|c|}{ Dryomys nitedula } & 1 & 0 & 1 & 0 & $0-94.54$ \\
\hline & \multicolumn{2}{|c|}{ Unknown } & 8 & 0 & 8 & 0 & $0-40.23$ \\
\hline \multirow{4}{*}{ Age } & \multicolumn{2}{|c|}{ Juveniles $0-2$ months old } & 57 & 5 & 52 & 8.77 & $3.27-20.04$ \\
\hline & \multicolumn{2}{|c|}{ Mature adult 3-6 months old } & 127 & 5 & 122 & 3.94 & $1.45-9.4$ \\
\hline & Adult c & old & 162 & 10 & 152 & 6.17 & $3.16-11.37$ \\
\hline & Unkno & & 128 & 20 & 108 & 15.62 & $10-23.34$ \\
\hline Total & & & 474 & 40 & 434 & 8.44 & $6.16-11.4$ \\
\hline
\end{tabular}

Table 1. T. gondii prevalence in small mammals trapped in Tatarstan, Russian Federation.

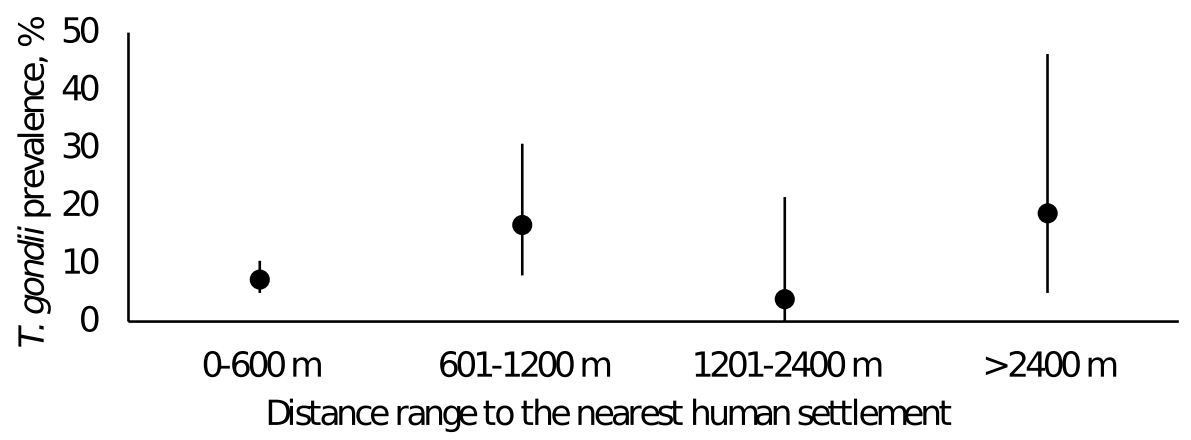

Figure 2. Prevalence of $T$. gondii B1-positive small mammals in each distance range to the nearest human settlement. Observed prevalence (black circles) and 95\% confidence intervals (black lines) are shown.

tion (forest or field), small mammal species type (alien or non-alien species), age (0-2 months-old juveniles, 3-6 months-old adults or $\geqq 6$ months-old), sex (male or female) and distance from the trapping point to the nearest human settlement. In the classification of small mammal species, small mammal species were classified as alien (A. agrarius, A. uralensis, A. flavicollis, Mi. arvalis) and non-alien (M. glareolus, S. araneus, D. nitedula) ${ }^{13}$. The forward selection procedure generated a model that included area, vegetation and the type of small mammal species that best fitted the data (Model 3, Supplementary Table S2). Other factors such as age, sex and distance 


\begin{tabular}{|l|l|r|}
\hline Predictor & Odds ratio $\mathbf{( 9 5 \%} \mathbf{C I})$ & \multicolumn{1}{|l|}{$\boldsymbol{p}$} \\
\hline Area & $3.92(1.90-8.40)$ & $<0.001$ \\
\hline Vegetation & - & 0.138 \\
\hline Species & - & 0.054 \\
\hline
\end{tabular}

Table 2. Risk factors for T. gondii infection.
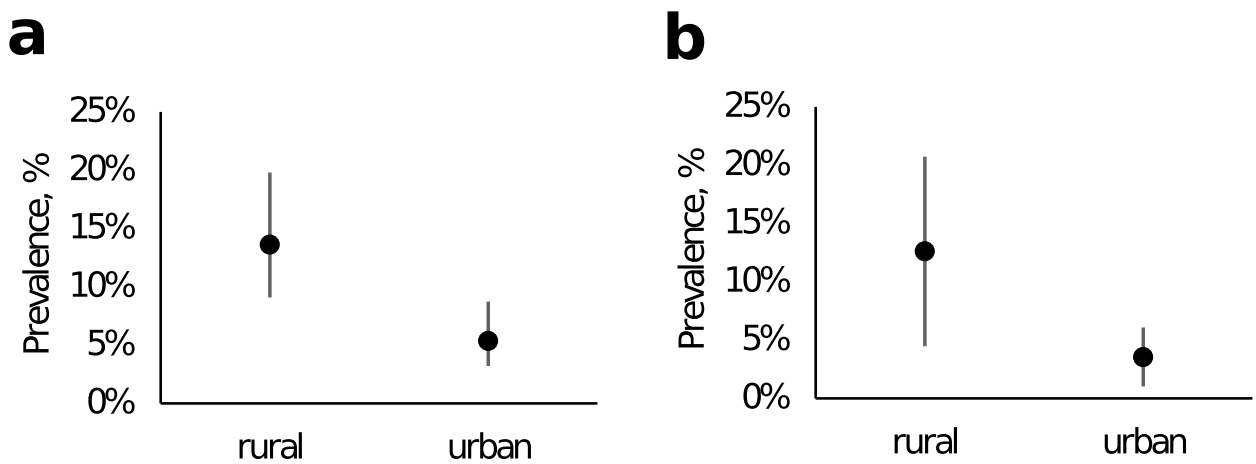

Figure 3. Observed and estimated T. gondii prevalences in rural and urban areas. (A) Observed prevalences among the small mammals captured in rural and urban areas. The observed prevalence and 95\% CIs are shown. (B) Estimated prevalences from the fitted model. Values for vegetation and species were set to zero (forest and non-alien species) in the model. Estimated prevalences (black circles) and 95\% CIs are shown.

from trapping points to the nearest human settlements were not included in the model. In this best fitted model, the only significant factor was the area, with neither vegetation nor species deemed significant (Table 2). The model identified rural area as a risk factor (Fig. 3). The actual observed prevalence of T. gondii infection was also significantly higher in the rural area than the urban area (Fig. 3).

\section{Discussion}

In this study, we surveyed T. gondii infection among small mammals in Tatarstan, Russian Federation. The overall T. gondii prevalence in these small mammals was $8.44 \%$. In addition to nested-PCR targeting the B1 gene, highly sensitive T. gondii DNA detection methods such as the LAMP method have been reported, but the sensitivities of these methods are similar with that of nested-PCR targeting the B1 gene ${ }^{14}$.

It was reported that more than $30 \%$ house mice, Mus musculus and Rattus rattus, in the Omsk city, Russian Federation were infected with $T$. gondii. However, as far as we know, there is no report about $T$. gondii prevalence among wild rodents in other area of Russian Federation ${ }^{15}$. In several European countries (France, Czech Republic, Sweden and Switzerland) the prevalence of T. gondii among wild small mammals living in rural forests was 3-7\%, which is not dissimilar to our results ${ }^{2}$. Using logistical regression analysis, we found that the trapping area (rural/ urban), but not the vegetation in the trapping spots, species, sex, age or distance from the trapping points to the nearest human settlements, significantly contributed to the prevalence of $T$. gondii among the small mammals. This result is reinforced by the fact that $T$. gondii infection prevalence among the small mammals trapped in the rural area was significantly higher statistically than that in the urban area.

Although the reason why small mammals in the rural area were more frequently infected with T. gondii is unknown, the ranging behavior of wild small mammals in the urban and rural areas might differ, thereby affecting the possibility of their exposure to T. gondii oocysts. Each small mammal species has a different habitat and range ${ }^{16-21}$. However, in this study, similar species were captured in rural and urban areas (Supplement Fig. S1). In this study, species-specific behavior cannot explain the higher prevalence of T. gondii infections in the ruralcaptured small mammals. If small mammals in rural areas have a bigger ranging behavior than those in urban areas it could result in more frequent exposure to T. gondii. However, it is not yet known whether the ranging behavior of the same small mammal species in rural and urban areas differs. It will therefore be necessary to investigate the behavior of each small mammal species living in such areas.

T. gondii infection in small mammals might also depend on the defecation habits of stray and free-ranging domestic cats in urban and rural areas. It was reported in France that the cat feces density in rural areas is higher than that in urban areas ${ }^{22}$. A similar situation may also exist in Tatarstan. In the present study, T. gondii infection was confirmed in a small mammal captured in a rural area $3.8 \mathrm{~km}$ from the nearest human settlement. T. gondiiinfected rodents were also found $2.5 \mathrm{~km}$ from the nearest human settlement in a rural area of London, $\mathrm{UK}^{2}$. In rural areas, the home-range size of free-ranging domestic cats is wider than that in urban areas ${ }^{2,8-12}$. Thus, it is possible that in the rural areas of the Tatarstan, Russian Federation, stray or free-ranging domestic cats deeply invade the forests and spread T. gondii oocysts in their fecal droppings. As far as we know, there are no reports of cat numbers or infection rates in the area and further investigation is needed. 
In addition to oocyst dissemination by cats, the methods used for garbage disposal in urban and rural areas might also affect $T$. gondii infection prevalence among wild animals. Unauthorized small-scale garbage collection sites are used in the rural forests of the Tatarstan, which both free-ranging domestic cats and wild animals can freely access. Hence, cysts contained in meat-derived food waste might be an infection source in these rural areas.

In this study, we show that T. gondii infection among wild small mammals in the rural area is, as a whole, significantly higher than in the urban area as a whole, regardless of the former being a greater distance from human activity zones. Therefore, further research is needed to clarify the source and route of T. gondii transmission in wild animals.

\section{Methods}

Study area and sampling. Small mammals (murid rodents and shrews) were captured using mouse-type snap traps in Tatarstan, Russian Federation (Fig. 1, Table S1). Area type (urban or rural), vegetation (forest or field) and distance from trapping points to the nearest human settlement were recorded. The distinction between forest and field was made based on the UN Food and Agriculture Organization's criteria ${ }^{23,24}$. Each administrative division in the Tatarstan was defined to be urban or rural by the Federal Service of State Statistics of Russian Federation $^{25}$. Based on these criteria, Kazan city and Naberezhnye Chelny city were classified as urban districts and Vysokogorsky district, Yelabuzhsky district, Laishevsky district, Mamadyshsky district, Nizhnekamsky district, Pestrechinsky district and Tukayevsky district were classified as rural districts. Small mammals were captured during the spring and fall periods of 2016 and 2017. Fifty traps were placed in a line every $5 \mathrm{~m}$ in one place. Traps were baited and left for one night. Animal suffering was minimized as snap traps cause rapid death in murid rodents and shrews. Each captured small mammal's species, age, and sex were morphologically identified using a reference guide ${ }^{26}$, and the animals were then stored at $-20^{\circ} \mathrm{C}$ until their brains were isolated.

Ethics. All experiments were performed in compliance with relevant Russian and Japanese and institutional laws and guidelines and were approved by the Ministry of Health of the Russian Federation and the Animal Research Committee of Gifu University (Permit Nos. MU 3.1.1029-01, and 17060, respectively). Study was carried out in compliance with the ARRIVE guidelines (https://arriveguidelines.org).

DNA extraction and PCR. Brain tissue samples were prepared as described previously ${ }^{12}$. Brain samples stored at $-20{ }^{\circ} \mathrm{C}$ were transferred to a $-86^{\circ} \mathrm{C}$ deep freezer. Each deep-frozen whole brain sample was homogenized in $1 \mathrm{ml}$ of a $0.9 \%$ saline solution. Total DNA was extracted from the brain tissues of each small mammal using a Genomic DNA Purification Kit (Promega, Madison, WI, USA), following the manufacturer's instructions. Nested PCR was performed with the Takara PCR Amplification Kit (Takara Bio Inc., Foster City, California, USA) according to the manufacturer's instructions. The primer sets and PCR conditions used to detect the B1 gene from T. gondii were those described previously ${ }^{12}$.

Mapping. Spatial referencing of the sampling sites was conducted using global positioning system navigation with a Garmin eTrex 10 device. Visualization of cartographic data and measurements of the distances from the trapping points to the nearest human settlements were performed using QGIS 3.12 software $^{27}$. Geodetic coordinates were projected into planar rectangular coordinates in the Universal Transverse Mercator projection on the WGS-84 ellipsoid (Universal Transverse Mercator, zone 39N). The overview map of the European part of Russia was made in the Lambert Conformal Conic Projection. Map coordinates are represented as geodetic coordinates (WGS-84, degrees and minutes north latitude and east longitude). To visualize thematic objects (administrative boundaries, forests, agricultural lands, and water bodies), a set of vector data layers, NextGIS (Russia), was purchased from OpenStreetMap and contributors, 2021 (https://data.nextgis.com). Data license: ODbL.

Dataset and statistical analyses. Multivariate logistic regression was performed using the R statistical software package (version 3.6.3) ${ }^{28}$ to assess the trapping point area (urban or rural), vegetation (forest or field), small mammal species type (alien or non-alien species), age (0-2 months-old juveniles, 3-6 months-old adults or $\geqq 6$ months old), sex (male or female) and distance from trapping points to the nearest human settlements as risk factors for PCR positivity. According to previous reports ${ }^{2,13,16-18}$, four species, Mi. arvalis, A. flavicollis, A. agrarius, A. uralensis, and three species, My. glareolus, S. araneus and D. nitedula are considered alien and non-alien species, respectively. Quantitative data were replaced with 0 or 1 dummy variables, and age data were replaced by 0,1 and 2 for juveniles, adults and elders, respectively. Multicollinearity of the explanatory variables was evaluated using Spearman's coefficient ${ }^{29}$ calculated using dplyr, FSA and psych packages ${ }^{30-32}$. None of the Spearman's coefficients were $>0.6$. To find the best fit model, a forward selection procedure was used. Predictive performance and model fitting were assessed using the area under the receiver operating characteristic (ROC) curve, area under the curve (AUC) and corrected Akaike's information criterion (AICc) with Akaike weight (Wi). AICc and Wi were calculated using the MuMIN package ${ }^{33}$, and the AUC was calculated using the R pROC package $^{34}$. $P$-values of $<0.05$ were considered statistically significant. The delta method was used to compute the standard errors for the predicted probabilities based on the multinomial logit function ${ }^{35}$. T. gondii prevalence confidence intervals $(95 \% \mathrm{CI}$ ) were estimated based on $468 / 474$ samples ( 6 samples were excluded from analysis because they lacked information). 


\section{Data availability}

The datasets generated during the current study are available from the corresponding author on reasonable request. All data analyzed during this study are included in this published article (and its Supplementary Information files).

Received: 16 February 2021; Accepted: 18 October 2021

Published online: 12 November 2021

\section{References}

1. Tenter, A. M., Heckeroth, A. R. \& Weiss, L. M. Toxoplasma gondii: from animals to humans. Int. J. Parasitol. 30, 1217-1258. https:// doi.org/10.1016/s0020-7519(00)00124-7 (2000) (published correction appears in Int. J. Parasitol. 31, 217-20 (2001)).

2. Dubey, J. P., Murata, F. H. A., Cerqueira-Cézar, C. K., Kwok, O. C. H. \& Su, C. Epidemiological significance of Toxoplasma gondii infections in wild rodents: 2009-2020. J. Parasitol. https://doi.org/10.1645/20-121 (2021).

3. Conrad, P. A. et al. Transmission of Toxoplasma: Clues from the study of sea otters as sentinels of Toxoplasma gondii flow into the marine environment. Int. J. Parasitol. https://doi.org/10.1016/j.ijpara.2005.07.002 (2005).

4. Loss, S. R., Will, T. \& Marra, P. P. The impact of free-ranging domestic cats on wildlife of the United States. Nat. Commun. https:// doi.org/10.1038/ncomms2380 (2013).

5. Howe, L., Hunter, S., Burrows, E. \& Roe, W. Four cases of fatal toxoplasmosis in three species of endemic New Zealand birds. Avian Dis. https://doi.org/10.1637/10625-080413-Case.1 (2014).

6. Work, T. M., Massey, J. G., Lindsay, D. S. \& Dubey, J. P. Toxoplasmosis in three species of native and introduced Hawaiian birds. J. Parasitol. https://doi.org/10.2307/3285558 (2002).

7. Honnold, S. P., Braun, R., Scott, D. P., Sreekumar, C. \& Dubey, J. P. Toxoplasmosis in a Hawaiian monk seal (Monachus schauinslandi). J. Parasitol. https://doi.org/10.1645/GE-469R (2005).

8. Quintero-Nunez, R. et al. Transmission of Toxoplasma gondii in Panama City, Panama: A five-year prospective cohort study of children, cats, rodents, birds, and soil. Am. J. Trop. Med. Hyg. 53, 458-468. https://doi.org/10.4269/ajtmh.1995.53.458 (1995).

9. Krauze-Gryz, D., Żmihorski, M. \& Gryz, J. Annual variation in prey composition of domestic cats in rural and urban environment. Urban Ecosyst. 20, 945-952. https://doi.org/10.1007/s11252-016-0634-1 (2017).

10. Red Book of the Republic of Tatarstan: animals, plants, mushrooms/Ministry of Forestry of the Republic of Tatarstan (and others; editor-in-chief: Nazirov A.A.). - 3rd edition. -Kazan: Ideal-press, 759 p. (2016).

11. Shuralev, E. A. et al. Toxoplasma gondii seroprevalence in goats, cats and humans in Russia. Parasitol. Int. https://doi.org/10.1016/j. parint.2017.10.014 (2018).

12. Shamaev, N. D. et al. Seroprevalence and B1 gene genotyping of Toxoplasma gondii in farmed European mink in the Republic of Tatarstan, Russia. Parasitol. Int. https://doi.org/10.1016/j.parint.2020.102067 (2020).

13. Khlyap, L. A., Warshavsky, A. A. \& Bobrov, V. V. Diversity of alien mammal species in different regions of Russia. Russ. J. Biol. Invasions. https://doi.org/10.1134/s2075111711040059 (2011).

14. Fallahi, S., Seyyed Tabaei, S. J., Pournia, Y., Zebardast, N. \& Kazemi, B. Comparison of loop-mediated isothermal amplification (LAMP) and nested-PCR assay targeting the RE and B1 gene for detection of Toxoplasma gondii in blood samples of children with leukaemia. Diagn. Microbiol. Infect. Dis. https://doi.org/10.1016/j.diagmicrobio.2014.02.014 (2014).

15. Sidorov, G. N. Zoonoticheskie infekcii i invazii domovoj myshi i seroj krysy v urbocenozah [Zoonotic infections and invasions of house mice and gray rats in urban cenoses. Veterinarnaya patologiya 2(17), 35-40 (2006).

16. Tolkachev, O. V. A study on the migrations of murine rodents in urban environments. Russ. J. Ecol. 47, 399-404. https://doi.org/ $10.1134 /$ S1067413616040147 (2016).

17. Vukićević-Radić, O., Matic, R., Kataranovski, D. \& Stamenković, S. Spatial organization and home range of Apodemus flavicollis and A. agrarius on Mt. Avala, Serbia. Acta Zoologica Academiae Scientiarum Hungaricae. 52, 81-96 (2006).

18. Musser, G. G. \& Carleton, M. D. Superfamily Muroidea. In Mammal Species of the World a Taxonomic and Geographic Reference (eds Wilson, D. E. \& Reeder, D. M.) 894-1531 (Johns Hopkins University Press, Baltimore, 2005).

19. Andreychev, A. V. \& Kiyaykina, O. S. Homing in the forest dormouse (Dryomys nitedula, Rodentia, Gliridae). Zoologicheskii zhurnal. 99, 698-705. https://doi.org/10.31857/S0044513420060033 (2020).

20. Mitter, G., Sumasgutner, P. \& Gamauf, A. Niche-partitioning of three Apodemus species (Mammalia: Murinae) in an urban environment. Annalen Des Naturhistorischen Museums Wien Serie B Für Botanik Und Zoologie 117, 37-46 (2015).

21. Dwużnik, D. et al. Comparison of helminth community of Apodemus agrarius and Apodemus flavicollis between urban and suburban populations of mice. Parasitol. Res. 116, 2995-3006. https://doi.org/10.1007/s00436-017-5609-5 (2017).

22. Knapp, J. et al. Rural and urban distribution of wild and domestic carnivore stools in the context of Echinococcus multilocularis environmental exposure. Int. J. Parasitol. https://doi.org/10.1016/j.ijpara.2018.05.007 (2018).

23. FAO. 2012a. FRA 2015 terms and definitions. Rome www.fao.org/docrep/017/ap862e/ap862e00.pdf (2012a).

24. FAO. FAOSTAT3. Glossary. http://faostat3.fao.org/mes/glossary/E (2016b).

25. "OK 033-2013. All-Russian Classifier of Territories of Municipal Formations" (Volume 1. Central Federal District) (approved by Order of Rosstandart dated 14.06.2013 N 159-st) (taking into account Changes 1/2013-418/2020).

26. Pavlinov, I. Y., Kruskop, K. S. V., Warsawsky, A. A., \& Borissenko, A. V. Terrestrial Mammals of Russia: A reference guide. Sci. Press. Moscow: KMK, p 298 (2002).

27. QGIS Development Team. QGIS Geographic Information System. Open Source Geospatial Foundation Project. http://qgis.osgeo. org (2020).

28. R Core Team. R: A language and environment for statistical computing. R Foundation for Statistical Computing, Vienna, Austria. https://www.R-project.org/ (2020).

29. Spearman, C. The proof and measurement of association between two things. Am. J. Psychol. 15, 72-101 (1904).

30. Wickham, H., François, R., Henry, L \& Müller, K. dplyr: A grammar of data manipulation. R package version 0.7.6. https://CRAN.Rproject.org/package $=$ dplyr (2018).

31. Revelle, W. psych: Procedures for Psychological, Psychometric, and Personality Research. Northwestern University, Evanston, Illinois. R package version 2.0.9, https://CRAN.R-project.org/package=psych (2020).

32. Ogle, D. H., Wheeler, P. \& Dinno, A. FSA: Fisheries Stock Analysis. R package version 0.8.30, https://github.com/droglenc/FSA (2020).

33. Bartoń, K. MuMIn: Multi-model inference. R package, version 0.12.2. http://r-forge.r-project.org/pro-jects/mumin/ (2009).

34. Robin, X. et al. pROC: An open-source package for R and S+ to analyze and compare ROC curves. BMC Bioinform. https://doi. org/10.1186/1471-2105-12-77 (2011).

35. Liu, X. Mixed-effects multinomial logit model for nominal outcomes. Methods Appl. Longit. Data Anal. https://doi.org/10.1016/ b978-0-12-801342-7.00011-3 (2016). 


\section{Acknowledgements}

This study was funded in part by the Russian Foundation for Basic Research (RFBR), Project No. 19-34-90024, and in part by the Research Program on Emerging and Re-emerging Infectious Diseases of the Japan Agency for Medical Research and Development (18fk0108010j0003 and 19fk0108047h0003), and the Joint Research Program of the Research Center for Zoonosis Control, Hokkaido University. We thank Sandra Cheesman, PhD, from Edanz Group (https://en-author-services.edanz.com/ac) for editing a draft of this manuscript.

\section{Author contributions}

N.D.S., Y.T., E.A.S. designed the experiments, investigated, analyzed and validated the data, and wrote the original draft of the manuscript. O.V.N., M.N.M., Y.N.D., A.N.B., G.Sh.I., V.B.Z., N.I.K., R.F.S., G.R.S., G.M.A., K.S.K., T.S., K.K. provided resources, and collected and curated the data. N.D.S., Y.T., E.A.S. acquired the funding for the experiments, administrated the project, wrote and revised the manuscript.

\section{Competing interests}

The authors declare no competing interests.

\section{Additional information}

Supplementary Information The online version contains supplementary material available at https://doi.org/ 10.1038/s41598-021-01582-y.

Correspondence and requests for materials should be addressed to Y.T.

Reprints and permissions information is available at www.nature.com/reprints.

Publisher's note Springer Nature remains neutral with regard to jurisdictional claims in published maps and institutional affiliations.

Open Access This article is licensed under a Creative Commons Attribution 4.0 International License, which permits use, sharing, adaptation, distribution and reproduction in any medium or format, as long as you give appropriate credit to the original author(s) and the source, provide a link to the Creative Commons licence, and indicate if changes were made. The images or other third party material in this article are included in the article's Creative Commons licence, unless indicated otherwise in a credit line to the material. If material is not included in the article's Creative Commons licence and your intended use is not permitted by statutory regulation or exceeds the permitted use, you will need to obtain permission directly from the copyright holder. To view a copy of this licence, visit http://creativecommons.org/licenses/by/4.0/.

(C) The Author(s) 2021 